\title{
A Novel Method for Leaf Area Estimation based on Hough Transform
}

Madhu Jadon

Dr. A. P. J. Abdul Kalam Technical University

Lucknow, India

madhujadon24@gmail.com

\begin{abstract}
Manual methods of Leaf area estimation are very time consuming and tiresome processes and these are generally inaccurate and subjective. A new approach is presented in this paper to make this process more accurate and user friendly by using Digital Image Processing techniques on leaves of healthy and diseased plants. A coin of five rupees is taken as a reference object to estimate the leaf area. Coins have been used in previous approaches in literature but none of the proposed methods have segmented coins accurately. Our method proposes a new approach for coin segmentation by using Hough transform. The main advantage of our proposed method is the area estimation of not only healthy leaves but also the diseased ones. Our method has been tested on four kinds of plants i.e. Potato, Pigeon Pea, Green Gram and Black Gram. Twenty leaves have been taken for each of these four plants in which ten leaves were healthy and remaining ten were of the diseased plants. The results obtained from this method were compared to the graph paper method. The average error rate of leaf area estimation of our proposed method are 1.49\%, 1.11\%, 1.71\% and 1.31\% for potato, Pigeon Pea, Green Gram and Black Gram respectively as compared to the results of graph paper method. It proves that our proposed method is more accurate for leaf area estimation of healthy and diseased leaves.
\end{abstract}

Keywords: LeafArea, Digital Image Processing, Hough Transform, Area Estimation

Received: 18 November 2017, Revised 17 January 2018, Accepted 29 January 2018

DOI: $10.6025 / \mathrm{jmpt} / 2018 / 9 / 2 / 33-44$

(C) 2018 DLINE. All Rights Reserved

\section{Introduction}

Leaves are very important part of a plant because plants make food in their leaves. The color of leaves is green due to the chlorophyll content present in leaves. Chlorophyll makes food from carbon dioxide, sunlight and water for the plant in the form of sugar and oxygen. This process is called photo synthesis. Area estimation of leaves is a vital tool for studying the physiological parameters based on plant growth, photosynthesis and transpiration processes. Leaf area estimation method is also beneficial to quantify the area damaged by diseases and pests [1]. Leaf area is one of the most important agronomic parameters as leaf area is directly related to plant growth and health. Additionally, the quantification of many growth analysis variables needs the measure-

Journal of Multimedia Processing and Technologies Volume 9 Number 2 June 2018 
ment of leaf area during the whole life cycle of the plant. Manual methods of leaf area estimation are tiresome, inaccurate and time consuming.

Traditional methods for leaf area estimation are paper weighing method, graph paper method and leaf area meter method. Paper weighing and graph paper methods are very simple and accurate but very slow. Although leaf area meter provides accurate results, but repetitions of experiment are required for a larger leaf which makes this process time consuming. Leaf area estimation methods can be classified into two broad categories as shown in the following figure1.

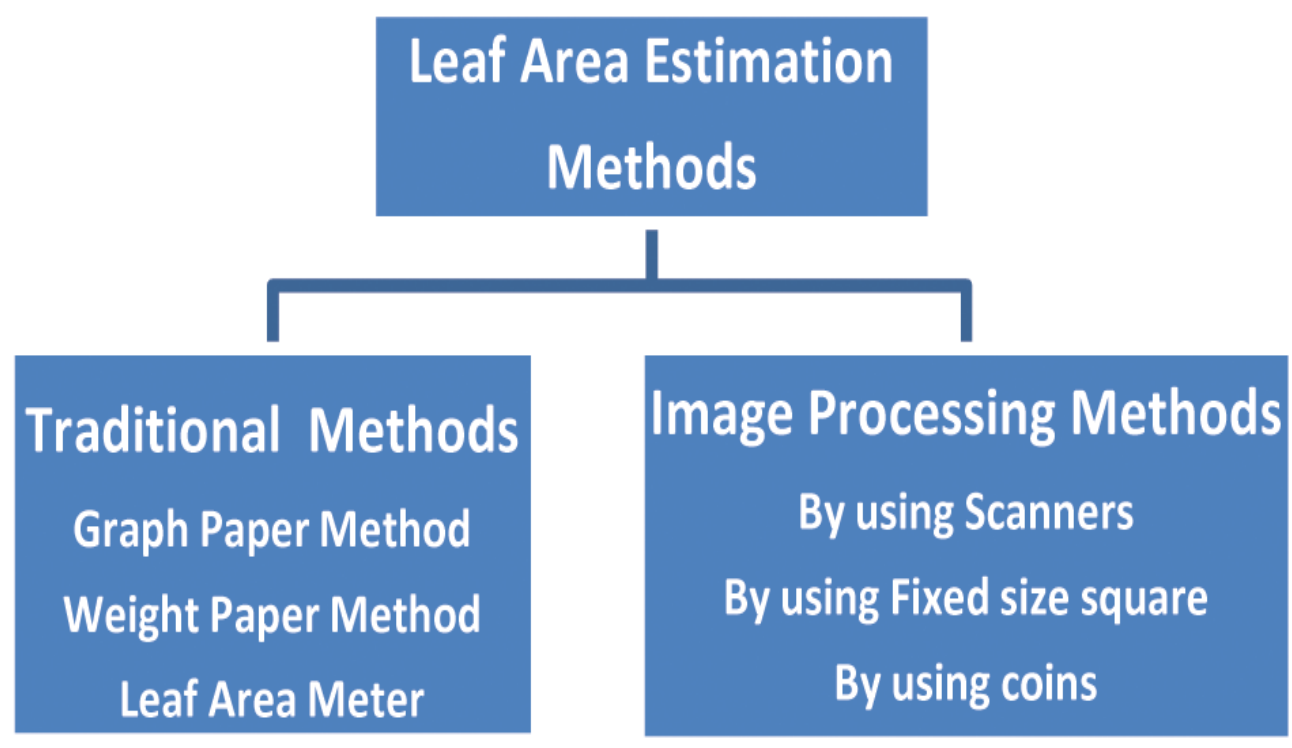

Figure 1. Different methods for leaf area estimation

Leaf area can either be estimated by using traditional methods or methods based on image processing. Nowadays, fast and accurate methods for leaf area estimations based on image processing are being adopted by modern agriculture technologies. Traditional methods must be repeated for each leaf sample for area estimation of leaves hence these methods are not suitable for large scale implementation. While in image processing methods, time is required only to implement the method once after that result can be obtained in seconds. Traditional methods are time consuming, destructive and not user friendly while Image processing methods are fast, non-destructive, low cost and user friendly.

\subsection{Traditional Methods}

\section{Graph Paper Method}

Firstly the detached leaf is placed on a graph paper then outline of the leaf is drawn by pencil on millimetre graph paper [2]. The leaf area is estimated by counting the number of small squares within the boundary. This method is accurate but laborious when there are large numbers of leaves for area estimation.

$$
\begin{aligned}
& \text { Leaf Area }=\text { Number of small squraes coverd by leaf } \\
& \times \text { Area of one small square }
\end{aligned}
$$

\section{Weight Paper Method}

Firstly the detached leaf is placed on a special paper and outline of the leaf is drawn by pencil on this paper [3]. The paper is cut according to outline of the leaf then Leaf area is calculated by weighing the paper and using the following formula:

$$
\text { Leaf Area }=\frac{\text { Weight of paper of leaf shape }}{\text { Weight of unit area of paper }}
$$

This method is also accurate but laborious when there are large number of leaves for area estimation.

$34 \quad$ Journal of Multimedia Processing and Technologies Volume 9 Number 2 June 2018




\section{Leaf Area Meter:}

Leaf area meter is a very convenient but costly device. These devices have been frequently used for area estimation due to their easy handling. Leaf area meter is not suitable for large sized leaves because large leaf has to be cut into smaller pieces then the area for each small piece has to be calculated individually and added to obtain the area of the whole leaf. Hence this makes use of leaf area meter very time consuming process for large leaves [5].

\subsection{Image Processing Methods}

An Image processing based method was proposed in [6, 7]. Leaves of brassica species, turmeric, soybean and wheat with different sizes and shapes have been used. The DOTNET framework as the front end and SQL server as the back end were used for leaf area calculation. Images of leaves were acquired with the help of digital scanner hence there were no need of any calibrating objects such as standard area, squares and coins. The colored RGB image was firstly converted into monochrome image by setting the threshold value in the color matrix. Leaf area was calculated by counting pixel numbers in leaf. The results were compared with the results of Leaf Area Meter developed by M/s Disha Infoway India Private Limited and it was concluded that the error rate between them is less than $\pm 2 \%$ for turmeric, brassica species, wheat and soybean leaves.

Easy Leaf Area software was developed to batch process hundreds of Arabidopsis rosette images in minutes and eliminating background details and saving results to a spreadsheet-ready CSV file [11]. Easy Leaf Area software calculates the color ratios of each pixel to distinguish leaves and calibration areas from their background. It compares numbers of pixels in leaf to a red calibration area to eliminate the need for leaf-camera distance calculations or manual ruler scale measurement that other software methods typically require. This method is fast and easy to use but the requirement of red square is must. This method is not suitable when the leaves were infected by brown color spots.

A method is proposed in [12] for estimating different parameters of leaf such as height, width, average width, area and perimeter. A digital scanner is used to acquire leaf images. Calibration object is not required in this method. Edge detection, filtering and thresholding algorithms are used to identify the leaf of the image in compared to the background. Forty leaves of different shapes and sizes were used to validate the estimated parameters as compared to the actual values and parameters generated by the popular leaf area meter Li-Cor 3100. This method is also fast and easy to use but the requirement of scanner is must.

A method is proposed in $[13,14,15]$ to estimate the leaf area with coin as a reference object. In this method, Coin has been segmented by Otsu method in gray channel but this method does not provide accurate results. There is a restriction in this method that coin must be darker than background.

Moreover, this method does not give accurate results for diseased leaves.

Our proposed method provides accurate results for both normal and diseased leaves; also there is no restriction on lightness or darkness of the coin than the background of the image which makes it a better model for practical use.

\section{Material and Method}

\subsection{Material}

A high resolution 24 Megapixels Digital Camera (Nikon D5300), White Paper Sheet, Leaves, Five Rupees Coin as a reference object, Computer to run Matlab, Matlab software (version 2014a), Millimeter Graph paper and Pencil have been used in this proposed method.

\subsection{Method}

The following flowchart depicts the basic process of this proposed method.

\subsubsection{Image Acquisition}

Twenty leaves each of four plants (i.e. Potato, Pigeon pea, Green Gram and Black Gram) have been used in this method in which ten leaves were healthy and remaining ten were the diseased leaves. Leaves samples were taken from Indian Institute of Pulse Research Center (IIPR), Kanpur. A five rupees coin and single leaf were placed on a white background paper then Images were taken by digital camera as shown in the following figures. Images were in RGB color space and in jpeg format. Leaves of each class are shown in the following figures 3-6. 


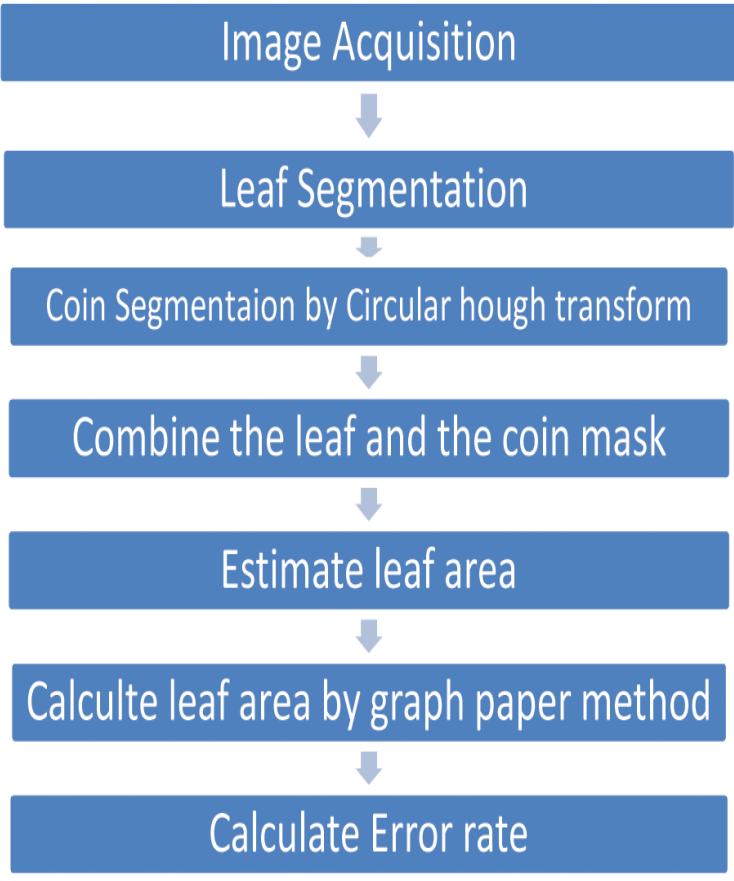

Figure 2. Block diagram of proposed method

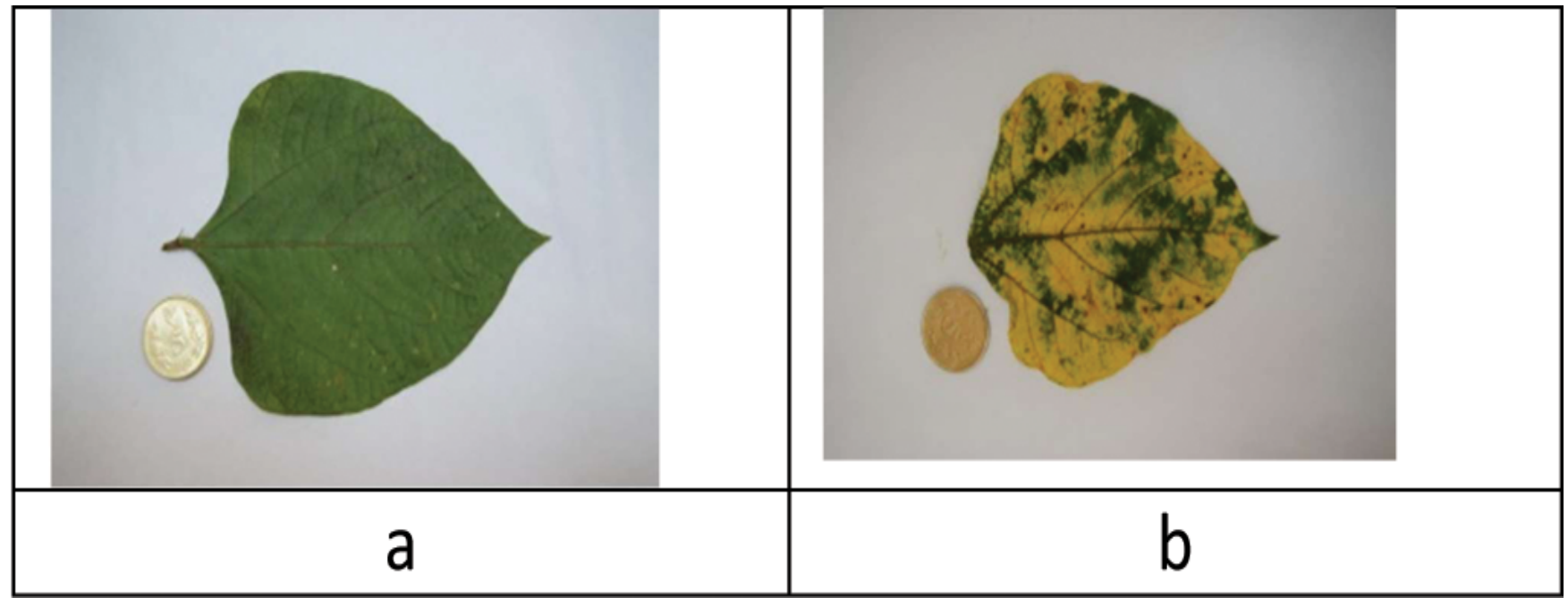

Figure 3. Sample Images of Green Gram with coin (a)Healthy (b) Infected

\subsubsection{Leaf Segmentation}

Leaf was segmented by Otsu method in gray color channel in other approaches $[13,14,15]$ by converting from RGB image to gray image based on the following Equation 3.

$$
\text { Gray VAlue }=0.2989 \times \text { Red }+0.5870 \times \text { Green }+0.1140 \times \text { Blue }
$$

Where Red, Green, Blue in equation (3) represents red, green and blue color of the pixels respectively [8]. Otsu method is an automatic threshold selection method. It assumes that an image is formed with a background and an object with different gray values, one gray value is taken as a threshold to segment the image into two classes; the background and the object, then the 


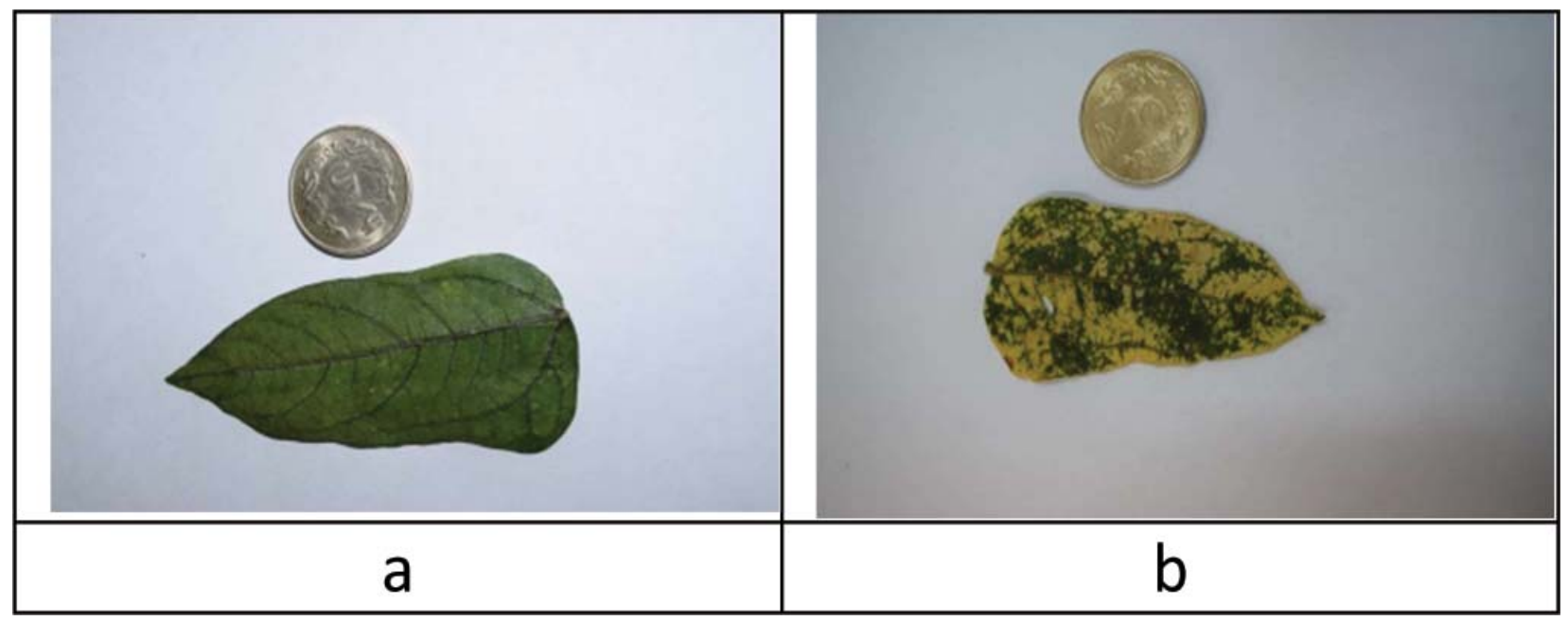

Figure 4. Sample Images of Black Gram with coin (a)Healthy (b)Infected

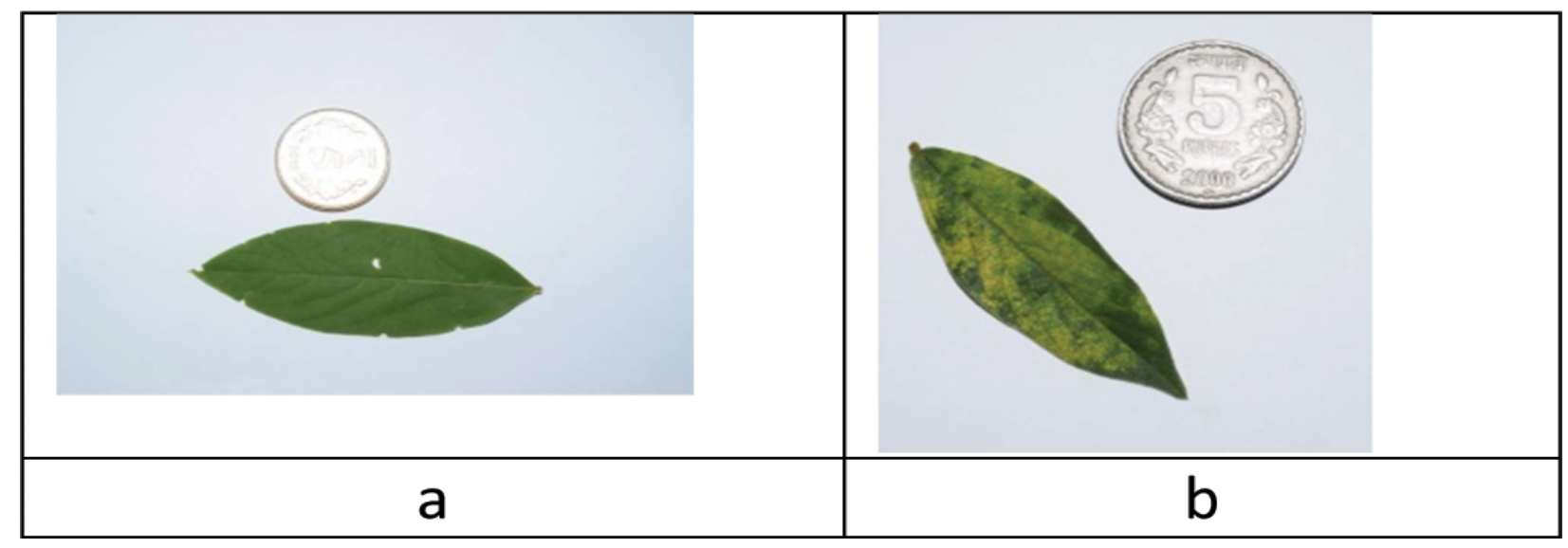

Figure 5. Sample Images of Pigeon Pea with coin (a)Healthy (b)Infected

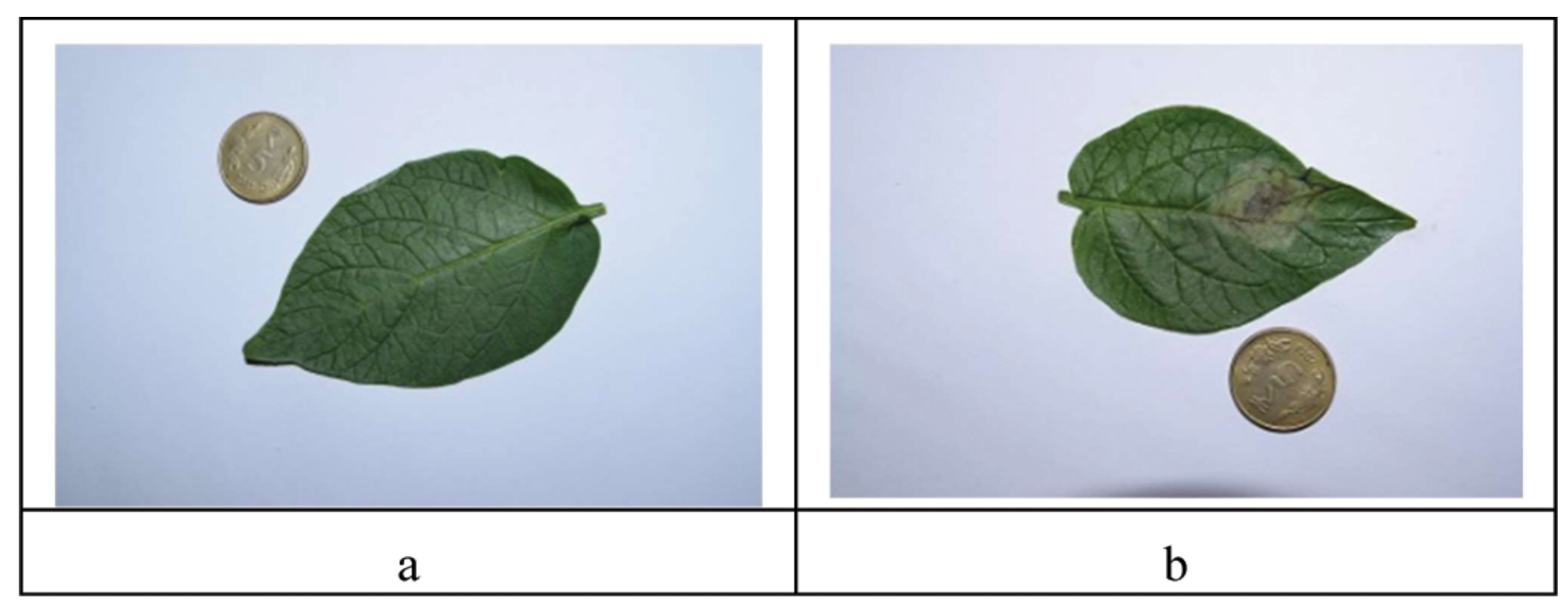

Figure 6. Sample Images of Potato with coin (a)Healthy(b)Infected 
variance between these two classes is calculated. When the largest variance is attained, this special gray value is applied as threshold [9].This segmentation does not give accurate results for diseased leaves as shown in the following figure 7. Some part of leaves are missing in this segmentation.

In our method, this problem has been solved by segmenting the leaf by Otsu method in blue color channel rather than gray value because blue color is more sensitive to any kind of the leaves (i.e healthy and diseased). Most of the blue color is absorbed by the leaves in comparison to red and green color channel. Blue color detail is minimized in above equation (1) for conversion from RGB to gray, hence it does not provide good segmentation results. In our proposed method Leaf segmentation gives very good results as shown in following figure 7.

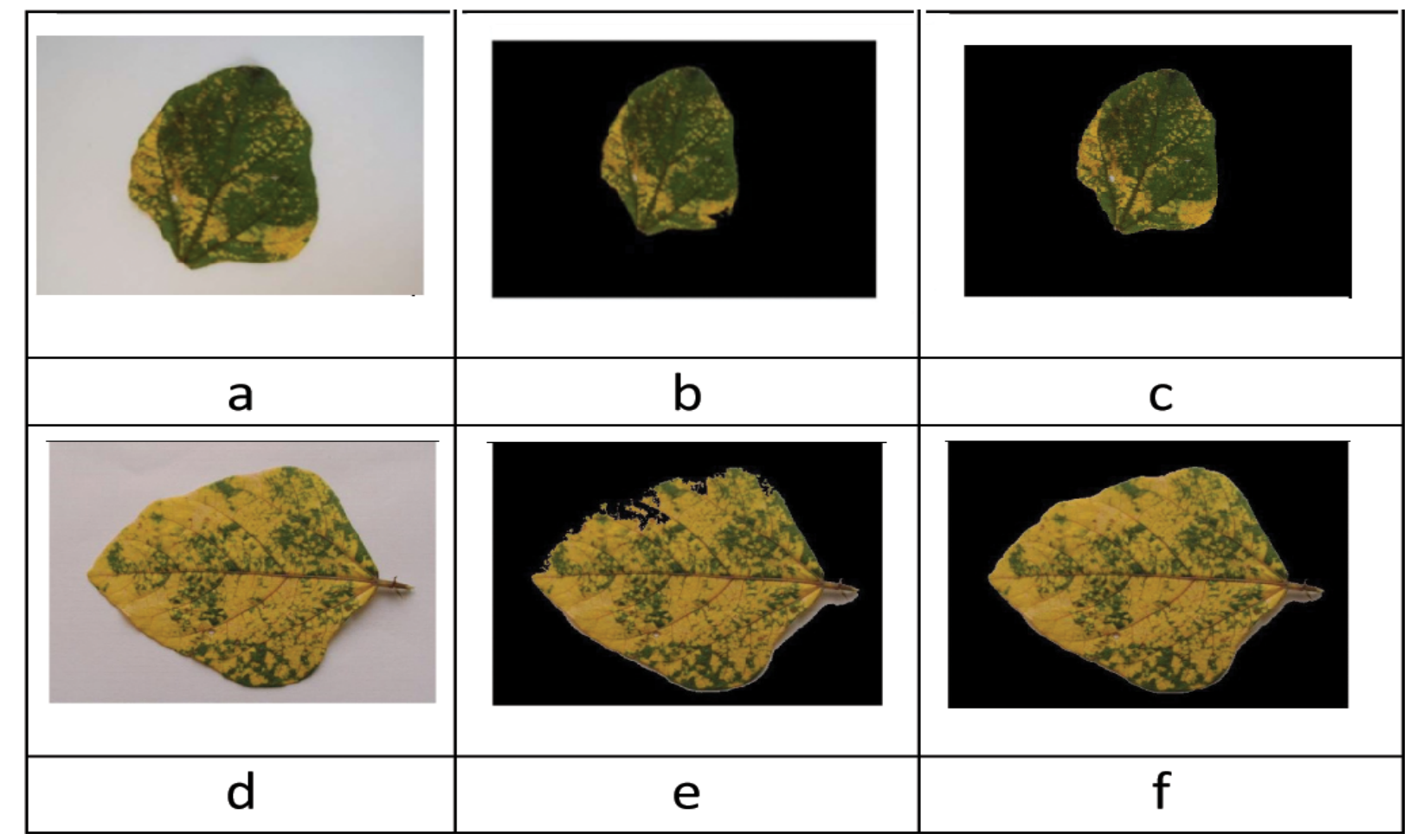

Figure 7. (a,d) Leaf Image (b,e) Segmented Image by Otsu method in gray channel, (c, f) segmented image by Otsu method in blue channel

\subsubsection{Coin Segmentation by Circular Hough Transform}

In [13-15], a simple coin segmentation technique has been used which works by thresholding the gray values by otsu method. These approaches are based on the fact that the coins itself are darker than its white background, but in real life situations it is not necessary that coins are darker than background. In Some cases coins are brighter than its background as shown in the following figure 8. Hence, in these cases coins cannot be segmented accurately by the methods in [13-15].

So, another solution must be explored for more accurate coin segmentation. Circular Hough transform is used in our proposed method for coin segmentation. The Hough transform is a very robust segmentation tool. The Hough transform technique has been used in many scientific applications. First time, Hough transform has been used to detect straight lines in bubble chamber data [16]. Circular Hough transform (CHT) is an extension of Hough Transform (HT) and it is used for detection of the circular objects from an image [18]. The circle pattern is defined by the following equation

$$
(x-a)^{2}+(y-b)^{2}=r^{2}
$$

Where $x$ and $y$ are the directions, $a$ and $b$ are the co-ordinates of the centre of the circle in $x, y$ direction, $r$ is the radius of the circle.

Circle is governed by three parameters i.e. $x$ and $y$ coordinates of the centre of the circle and the radius $r$ of the circle therefore 
Hough space is a three dimensional space for detection of circular objects. In order to perform Circular Hough Transform all possible values of radius may be considered but in our proposed method some range of radius has been taken which is suitable for coins. Results of Circular Hough transform are shown in following figure 8:

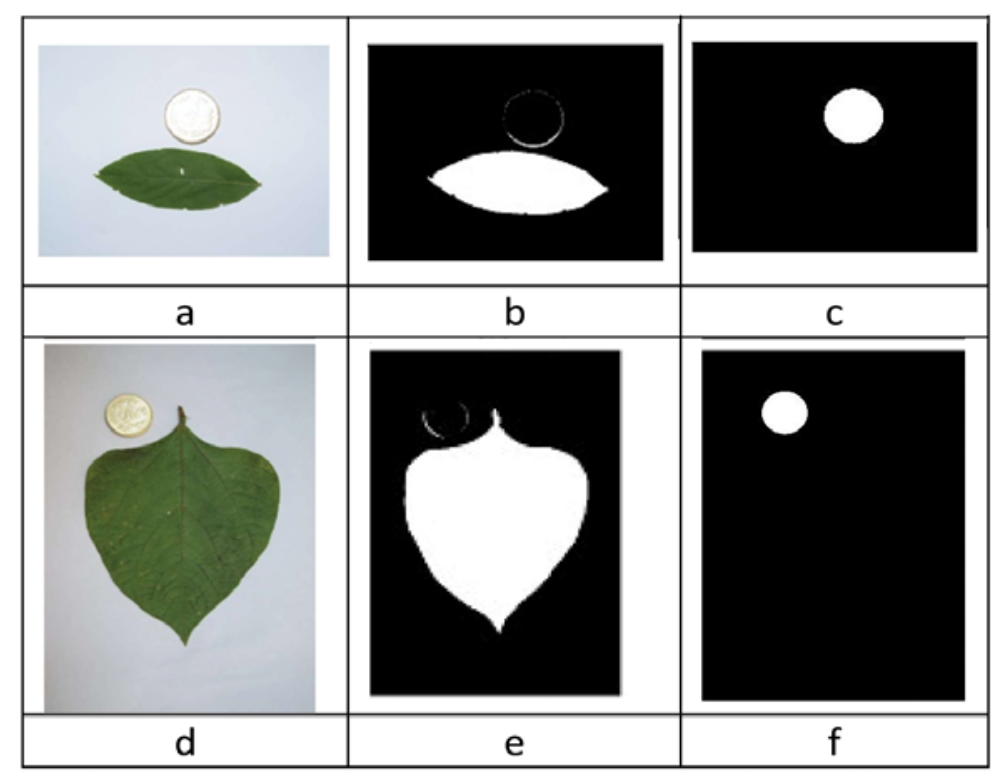

Figure 8. (a, d) Leaf Image with coin, (b, e) Segmented Image by Otsu method in gray channel, (c, f) segmented image by Circular Hough Transform

\subsubsection{Combine the Leaf and Coin Mask}

In step 2 and 3 of our method, leaf mask and coin mask were obtained respectively. Now both of these masks were combined by logical OR operation. It is performed in bitwise manner on the binary values of each pixel in the images. In combined mask ' 1 ' represents either leaf or coin and '0' represents background pixels. The result of this step is shown in the following figure 9:

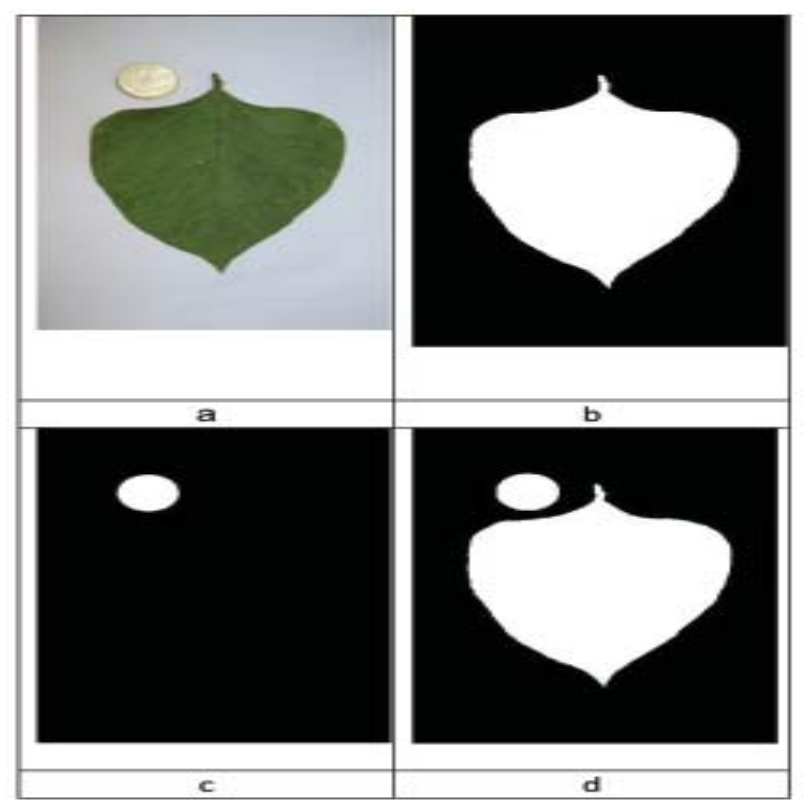

Figure 9. (a) Leaf Image with coin, (b) Segmented Image in step 2, (c) segmented image in step 3 (d) Combination of Leaf and coin mask 


\subsubsection{Estimate Leaf Area}

There are only two connected components in Figure 9(d); i.e. leaf and coin. $N_{\text {leaf }}$ and $N_{\text {coin }}$ denotes the total number of pixels in leaf and coin mask respectively. Code is written for calculating $N_{\text {leaf }}$ and $N_{\text {coin }}$ in MATLAB 2014.

Leaf area is estimated by the following equation

$$
A_{\text {leaf }}=\frac{A_{\text {coin }} \times N_{\text {leaf }}}{N_{\text {coin }}} \text { in centimeter }{ }^{2}
$$

Where

$A_{\text {leaf }}$ is defined as the leaf area calculated by proposed method in centimeter ${ }^{2}$.

$A_{\text {coin }}$ is defined as the area of used coin measured in centimeter ${ }^{2}$.

$$
A_{\text {coin }}=\pi \times \text { radius }^{2}
$$

Where 'radius' is defined as the radius of the coin used in this method.

The radius of the coin used in this method is 1.15 centimetre so the value of $A_{\text {coin }}$ is 4.155 centimetre 2 .

\subsubsection{Calculate Area by Graph Paper Method}

For comparison of leaf area estimated by proposed method with the Graph Paper Method, leaf is placed on millimetre graph paper then leaf border is outlined by the help of the pencil. All squares are counted within the boundary of the leaf.

$$
A_{\text {graph }}=\frac{\text { Number of small square coverd by leaf }}{100} \mathrm{Cm}^{2}
$$

\subsubsection{Calculate Error Rate}

Error rate is defined by the following equation. $A_{\text {leaf }}$ and $A_{\text {graph }}$ were calculated in step 5 and 6 respectively.

$$
\text { Error Rate }(E R)=\frac{\left|A_{\text {grap }}-\mathrm{A}_{\text {leaf }}\right|}{A_{\text {graph }}} \times 100 \%
$$

\section{Results and Conclusion}

Twenty leaves each of four plants have been taken in this method in which ten leaves are healthy and remaining ten leaves are diseased. Leaf Area is calculated by using proposed method and graph paper method. Error rate is calculated by using equation 5. Results are shown in the Table- 1 to Table- 4 for different types of plants. This method can be used for leaf area estimation by using any circular coin available. Our method also prompts a message to re-capture the leaf image in case image does not contain coin with the leaf.

A more accurate, novel and automatic method is proposed in this paper based on image processing techniques. Coins are used in this method instead of scanner, ruler and square of different color or any standard area. Therefore our method is more accurate and user friendly. While taking images, camera lens plane must be perpendicular to leaf plane to eliminate area measurement errors due to generated shadow and perspective distortion. The average error rate of leaf area estimation of proposed method are $1.49 \%$, $1.11 \%, 1.71 \%$ and $1.31 \%$ for potato, Pigeon Pea, Green Gram and Black Gram respectively as compared to the results of graph paper method.

\section{Future Scope}

For future research, there are some directions as following:

\begin{tabular}{llllll}
\hline $40 \quad$ Journal of Multimedia Processing and Technologies & Volume & 9 & Number 2 & June & 2018 \\
\hline
\end{tabular}




\begin{tabular}{|c|c|c|l|l|l|l|l|}
\hline $\begin{array}{c}\text { Leaf } \\
\text { Image } \\
\text { No. } \\
\text { Healthy }\end{array}$ & $\begin{array}{c}\text { Area by } \\
\text { proposed } \\
\text { Method } \\
\text { (cm2) }\end{array}$ & $\begin{array}{c}\text { Millime- } \\
\text { ter } \\
\text { graph } \\
\text { paper } \\
\text { method } \\
\text { (cm2) }\end{array}$ & $\begin{array}{c}\text { Error } \\
\text { Rate } \\
\mathbf{( \% )}\end{array}$ & $\begin{array}{c}\text { Leaf } \\
\text { Image } \\
\text { No. } \\
\text { In- } \\
\text { fected }\end{array}$ & $\begin{array}{c}\text { Area by } \\
\text { proposed } \\
\text { Method } \\
\text { (cm2) }\end{array}$ & $\begin{array}{c}\text { Area } \\
\text { by } \\
\text { Milli- } \\
\text { graph } \\
\text { paper } \\
\text { method } \\
\text { (cm2) }\end{array}$ & $\begin{array}{c}\text { Error } \\
\text { Rate } \\
\mathbf{( \% )}\end{array}$ \\
\hline 1 & 18.47 & 18.1 & 2.04 & 11 & 24.13 & 23.89 & 1.00 \\
\hline 2 & 22.55 & 22.32 & 1.03 & 12 & 16.05 & 15.89 & 1.01 \\
\hline 3 & 38.26 & 37.4 & 2.30 & 13 & 20.67 & 20.45 & 1.08 \\
\hline 4 & 20.72 & 20.56 & 0.78 & 14 & 25.76 & 25.43 & 1.30 \\
\hline 5 & 28.76 & 29.2 & 1.51 & 15 & 23.56 & 23.12 & 1.90 \\
\hline 6 & 21.78 & 21.35 & 2.01 & 16 & 30.44 & 30.17 & 0.89 \\
\hline 7 & 22.65 & 22.2 & 2.03 & 17 & 31.56 & 30.98 & 1.87 \\
\hline 8 & 32.78 & 32.34 & 1.36 & 18 & 34.65 & 34.08 & 1.67 \\
\hline 9 & 37.14 & 36.8 & 0.92 & 19 & 28.98 & 28.22 & 2.69 \\
\hline 10 & 20.46 & 20.2 & 1.29 & 20 & 30.2 & 29.88 & 1.07 \\
\hline Average & & & 1.53 & & & & 1.45 \\
\hline
\end{tabular}

Table 1. The error rate of proposed method of healthy and diseased leaves of Potato

- The proposed Method can be integrated in real life automated vehicle to monitor the plant growth.

- New mobile android app can be developed based on this method so that it will be easy and more convenient for plant growers.

\section{Limitations}

There are some limitations of proposed method as following:

- Camera lens plane must be kept perpendicular to the leaf plane to avoid perspective distortion.

- No shadow should be formed for achieving high accuracy.

\section{References}

[1] Ali, H., Anjum, M. A. (2004). Aerial growth and dry matter production of Potato (Solanum tuberosum L.) cv. Desiree in relation to Phosphorus application, International Journal of Agriculture and Biology, 6 (3) 458-461.

[2] Caldas, L. S., Bravo, C., Piccolo, H., Faria, C. R. S. M. (1992). Measurement of Leaf Area with a Hand-Scanner linked to a microcomputer, R. Bras. Fisiol. Veg. 4 (1) 17-20. 


\begin{tabular}{|c|c|c|c|c|c|c|c|}
\hline $\begin{array}{c}\text { Leaf } \\
\text { Image } \\
\text { No. } \\
\text { Healthy }\end{array}$ & $\begin{array}{c}\text { Area by } \\
\text { proposed } \\
\text { Method } \\
\text { (cm2) }\end{array}$ & $\begin{array}{c}\text { Areaby } \\
\text { Millime- } \\
\text { ter } \\
\text { graph } \\
\text { paper } \\
\text { method } \\
\text { (cm2) }\end{array}$ & $\begin{array}{c}\text { Error } \\
\text { Rate } \\
\mathbf{( \% )}\end{array}$ & $\begin{array}{c}\text { Leaf } \\
\text { Image } \\
\text { No. } \\
\text { In- } \\
\text { fected }\end{array}$ & $\begin{array}{c}\text { Area by } \\
\text { proposed } \\
\text { Method } \\
\text { (cm2) }\end{array}$ & $\begin{array}{c}\text { Areaby } \\
\text { Millime- } \\
\text { ter } \\
\text { graph } \\
\text { paper } \\
\text { method } \\
\text { (cm2) }\end{array}$ & $\begin{array}{c}\text { Error } \\
\text { Rate } \\
\mathbf{( \% )}\end{array}$ \\
\hline 1 & 78.44 & 76.96 & 1.92 & 11 & 71.56 & 70.08 & 2.11 \\
\hline 2 & 71.65 & 70.42 & 1.75 & 12 & 72.12 & 71.42 & 0.98 \\
\hline 3 & 80.25 & 80.02 & 0.29 & 13 & 69.45 & 68.11 & 1.97 \\
\hline 4 & 76.98 & 74.78 & 2.94 & 14 & 62.76 & 61.94 & 1.32 \\
\hline 5 & 72.43 & 71.2 & 1.73 & 15 & 58.35 & 57.32 & 1.80 \\
\hline 6 & 70.56 & 68.94 & 2.35 & 16 & 65.98 & 66.23 & 0.38 \\
\hline 7 & 71.65 & 70.34 & 1.86 & 17 & 73.78 & 71.98 & 2.50 \\
\hline 8 & 76.25 & 75.26 & 1.32 & 18 & 80.5 & 79.12 & 1.74 \\
\hline 9 & 71.98 & 70.25 & 2.46 & 19 & 71.65 & 69.97 & 2.40 \\
\hline 10 & 74.98 & 73.89 & 1.48 & 20 & 65.35 & 64.76 & 0.91 \\
\hline Average & & & 1.81 & & & & 1.61 \\
\hline
\end{tabular}

Table 3. The error rate of proposed method of healthy and diseased leaves of Green Gram

[14] Vasifa Aglave, A., Sambreand, N. B., Patil, S. B. (2012). Estimating Leaf Area By Using Imaging Technique, IJAIR, 346-35.

[15] Jadon, M., Agarwal, R., Singh, R. (2016). An easy method for leaf area estimation based on digital images, In: Proc. of International Conference on Computational Techniques in Information and Communication Technologies (ICCTICT), New Delhi, 2016, p. 307-310.

[16] Parmar, D. K., Ghodasara, Y. R., Patel, K. P., Patel, K. V., Kathiriya, D. R. (2015). Estimation of Plant Leaf Area using Java Image Processing Techniques, International Journal on Recent and Innovation Trends in Computing and Communication, 3 (2) (February).

[17] Hough, P. V. C. (1962). Method and means of recognizing complex patterns, US patent 3069654 (December).

[18] Ballard, D. H. (1981). Generalizing the hough transform to detect arbitrary shapes. Pattern Recognition, 13-2. 


\begin{tabular}{|c|c|c|c|c|c|c|c|}
\hline $\begin{array}{c}\text { Leaf } \\
\text { Image } \\
\text { No. } \\
\text { Healthy }\end{array}$ & $\begin{array}{l}\text { Area by } \\
\text { proposed } \\
\text { Method } \\
(\mathrm{cm} 2)\end{array}$ & $\begin{array}{c}\text { Areaby } \\
\text { Millime- } \\
\text { ter } \\
\text { graph } \\
\text { paper } \\
\text { method } \\
\text { (cm2) }\end{array}$ & $\begin{array}{c}\text { Error } \\
\text { Rate } \\
(\%)\end{array}$ & $\begin{array}{c}\text { Leaf } \\
\text { Image } \\
\text { No. } \\
\text { In- } \\
\text { fected }\end{array}$ & $\begin{array}{c}\text { Area by } \\
\text { proposed } \\
\text { Method } \\
(\mathrm{cm} 2)\end{array}$ & $\begin{array}{c}\text { Areaby } \\
\text { Millime- } \\
\text { ter } \\
\text { graph } \\
\text { paper } \\
\text { method } \\
\text { (cm2) }\end{array}$ & $\begin{array}{c}\text { Error } \\
\text { Rate } \\
(\%)\end{array}$ \\
\hline 1 & 30.41 & 29.97 & 1.47 & 11 & 22.13 & 21.96 & 0.77 \\
\hline 2 & 37.16 & 37.79 & 1.67 & 12 & 23.56 & 22.98 & 2.52 \\
\hline 3 & 28.27 & 28.03 & 0.86 & 13 & 26.98 & 27.32 & 1.24 \\
\hline 4 & 25.18 & 24.96 & 0.88 & 14 & 32.67 & 32.31 & 1.11 \\
\hline 5 & 40.32 & 39.87 & 1.13 & 15 & 31.54 & 31.11 & 1.38 \\
\hline 6 & 35.56 & 35.12 & 1.25 & 16 & 28.2 & 28.45 & 0.88 \\
\hline 7 & 32.97 & 33.66 & 2.05 & 17 & 29.88 & 29.23 & 2.22 \\
\hline 8 & 31.23 & 31.74 & 1.61 & 18 & 36.34 & 36.05 & 0.80 \\
\hline 9 & 30.76 & 30.2 & 1.85 & 19 & 33.23 & 32.93 & 0.91 \\
\hline 10 & 28.92 & 29.16 & 0.82 & 20 & 31.18 & 30.92 & 0.84 \\
\hline Average & & & 1.36 & & & & 1.27 \\
\hline
\end{tabular}

Table 4. The error rate of proposed method of healthy and diseased leaves of Black Gram 